\title{
Revision and phylogeny of Rhamnocercinae Monaco, Wood et Mizelle, 1954 (Monogenoidea: Diplectanidae)
}

\author{
Marcus V. Domingues ${ }^{1,2}$ and Walter A. Boeger ${ }^{1}$ \\ ${ }^{1}$ Curso de Pós Graduação, Zoologia, Laboratório de Parasitologia Evolutiva, Departamento de Zoologia, Universidade Federal do \\ Paraná, Caixa Postal 19073, 81531-980 Curitiba, PR, Brasil; \\ ${ }^{2}$ Laboratório de Helmintologia Evolutiva, Instituto de Biociências, Universidade de São Paulo, Rua do Matão, trav. 14, no. 321, \\ 05508-900 São Paulo, SP, Brasil
}

Key words: Monogenoidea, Diplectanidae, Rhamnocercinae, Rhamnocercus, Rhamnocercoides, Spinomatrix, revision, phylogeny

\begin{abstract}
Species of Rhamnocercinae Monaco, Wood et Mizelle, 1954 are gill parasites of sciaenid fishes (Perciformes). Seven are marine species (three in the western Atlantic and four in oriental Pacific) and one is a neotropical freshwater species (Rio Doce Basin, Brazil). While the status of the subfamily may be questioned, this assemblage of species is apparently supported by several shared apomorphic and plesiomorphic characters, such as: (1) peduncular spines with anterior and posterior roots; (2) haptor laterally expanded, armed with anchors (two pairs); bars (one ventral, two dorsal); 14 hooks and haptoral accessory spines; and (3) double (nested) tubes of the male copulatory organ (MCO), directed posteriorly with the genital pore lying posterior to the MCO. The phylogenetic hypothesis for the eight known species of this clade is: (Spinomatrix penteormos (Rhamnocercoides stichospinus, Rhamnocercoides menticirrhi) Rhamnocercus oliveri (Rhamnocercus rhamnocercus (Rhamnocercus stelliferi, Rhamnocercus bairdiella, Rhamnocercus margaritae)). This hypothesis indicates that Spinomatrix penteormos represents the sister group of all remaining rhamnocercines. The resulting phylogenetic sister-group relationships support the transfer of Rhamnocercus stichospinus Seamster et Wood, 1956 to Rhamnocercoides Luque et Iannacone, 1991 as Rhamnocercoides stichospinus (Seamster et Wood, 1956) n. comb.
\end{abstract}

Monaco et al. (1954) proposed the Rhamnocercinae to accommodate diplectanid species with the following characteristics: (1) absence of squamodiscs and (2) presence of parenchymatic spines in the haptor and peduncle. Hargis (1955) rejected the Rhamnocercinae based on the proposed homology of the dorsal and ventral "plates" (parenchymatic spines, sensu Monaco et al. 1954) of rhamnocercines and the squamodiscs of other diplectanids. Seamster and Monaco (1956) rejected the proposal of Hargis (1955) and continued to recognise the Rhamnocercinae as valid. Oliver (1987) proposed elevation of the Rhamnocercinae to the family level within the Heterotesioidea based on the confluent condition of the gut. Chaves et al. (1999) rejected this change in category but considered that species of this taxon possess confluent intestinal caeca as suggested by Hargis (1955), Luque and Iannacone (1991) and Oliver (1987). Chaves et al. (1999) recommended that a possible change in category would only be justifiable if based on a phylogenetic analysis of the Diplectanidae. Desdevises et al. (2001) accepted Oliver's decision (1987) and proposed a phylogenetic hypothesis for genera of Diplectanidae. Obviously, species of Rhamnocercoides and Rhamnocercus were not considered in their phylogenetic analysis.

While the taxonomic status of this group of species remains uncertain, its eight species depict a unique character that may represent a synapomorphy, supporting its natural condition. Its species are gill parasites of sciaenids (Perciformes, Sciaenidae) and share the presence of peduncular spines with deep and superficial roots. Thus, in this paper, the species included in Rhamnocercinae are revised based on a phylogenetic hypothesis.

\section{MATERIALS AND METHODS}

This study is based on both museum and collected specimens. Menticirrhus americanus (Linnaeus, 1758) (Sciaenidae) was collected during April and July 2001 in Balneário Pontal do Sul, Municipality of Pontal do Paraná, State of Paraná, Brazil, with hook-and-line and gill nets. Host gills were removed and placed in vials containing heated $\left(65^{\circ} \mathrm{C}\right) 4 \%$ formalin solution. Some helminths were mounted unstained in Hoyer's medium for study of sclerotized structures (Humason 1979). Other specimens were stained with Gomori's trichrome to determine internal features (Humason 1979). Drawings (Figs. 1-46) were prepared with the aid of a camera lucida. Measurements, all in micrometres $(\mu \mathrm{m})$, were made according to the procedures of Mizelle and Klucka (1953); the mean is followed by the range and the number ( $\mathrm{n}$ ) of specimens measured in parentheses. Numbering of hook pairs follows the recommendation of Mizelle (1936).

Type specimens and vouchers are deposited in the Coleção Helmintológica do Instituto Oswaldo Cruz, Rio de Janeiro,

Address for correspondence: M.V. Domingues, Laboratório de Helmintologia Evolutiva, Instituto de Biociências, Universidade de São Paulo, Rua do Matão, trav. 14, no. 321, Cidade Universitária, 05508-900 São Paulo, SP, Brasil. Phone: ++55 1130917481 ;

E-mail: mvdomingues@ib.usp.br 
Table 1. Characters used in the phylogenetic reconstruction. Numbers in parentheses preceding the definition of a character state refer to the coding that state received in the matrix. Bold numbers in brackets following the definition refer to respective evolutionary changes depicted in the cladogram (Fig. 47). The character matrix used for this analysis is presented in Table 2.

\begin{tabular}{|c|c|c|c|}
\hline 1 & Vagina & (0) muscular [23] & (1) sclerotized [14] \\
\hline 2 & Squamodiscs & (0) present & (1) absent [15] \\
\hline 3 & Peduncular spines & (0) absent & (1) present [13] (Fig. 6) \\
\hline 4 & Base of the peduncular spines & $\begin{array}{l}\text { (0) anterior root larger } \\
\text { than posterior root }\end{array}$ & (1) posterior root larger than anterior root [16] \\
\hline 5 & $\begin{array}{l}\text { Shape of the distal portion of the haptoral } \\
\text { accessory spines at the level of the ventral } \\
\text { bar }\end{array}$ & $\begin{array}{l}(0) \text { acicular (Figs. 20, 30, } \\
35,36)\end{array}$ & (1) expanded in fan form [19] (Fig. 3) \\
\hline 6 & $\begin{array}{l}\text { Number of haptoral accessory spines at the } \\
\text { level of the ventral bar }\end{array}$ & (0) more than 6 (Fig. 6) & $\begin{array}{l}\text { (1) } 3 \text { or } 6 \text { (Figs. 20, 30, 35, 36; fig. } 20 \text { of Luque } \\
\text { and Iannacone 1991) [21] }\end{array}$ \\
\hline 7 & $\begin{array}{l}\text { Haptoral accessory spines associated with } \\
\text { the haptoral lobes }\end{array}$ & (0) absent & (1) present (Fig. 6) [17] \\
\hline 8 & Posteromedial projection of the ventral bar & (0) absent & (1) present [18] (Figs. 13, 17, 28, 34, 42) \\
\hline 9 & $\begin{array}{l}\text { Anteromedial constriction of the ventral } \\
\text { bar }\end{array}$ & (0) absent & (1) present [20] (Fig. 13) \\
\hline 10 & Shape of the male copulatory organ (MCO) & (0) straight (Figs. 7, 16) & (1) sinuous [25] (Figs. 25, 31, 41) \\
\hline 11 & $\begin{array}{l}\text { Shape of distal portion of the external tube } \\
\text { of the MCO }\end{array}$ & $\begin{array}{l}\text { (0) expanded and twisted } \\
\text { (Figs. } 1,7)\end{array}$ & (1) uniform [22] (Figs. 16, 25, 31, 41) \\
\hline 12 & Internal tube of the $\mathrm{MCO}$ & $\begin{array}{l}\text { (0) not juxtaposed to the } \\
\text { external tube (Figs. } 1,7)\end{array}$ & $\begin{array}{l}\text { (1) juxtaposed to the external tube [24] (Figs. 16, } \\
25,31,41)\end{array}$ \\
\hline
\end{tabular}

Table 2. Character matrix used in reconstruction of the evolutionary relationships of the Rhamnocercinae.

\begin{tabular}{lcccccccccccc}
\hline Taxa/characters* & 1 & 2 & 3 & 4 & 5 & 6 & 7 & 8 & 9 & 10 & 11 & 12 \\
\hline Lepidotrema therapon & 0 & 0 & 0 & - & 0 & 0 & 0 & 0 & 0 & 0 & 0 & 0 \\
Spinomatrix penteormos & 0 & 0 & 1 & 1 & 0 & 0 & 0 & 0 & 0 & 0 & 0 & 0 \\
Rhamnocercoides menticirrhi & 1 & 1 & - & 0 & 1 & 0 & 1 & - & 1 & 0 & 0 & 0 \\
Rhamnocercoides stichospinus & 1 & 1 & 1 & 0 & 1 & 0 & 1 & 1 & 1 & 0 & 0 & 0 \\
Rhamnocercus oliveri & 1 & 1 & 1 & 0 & 0 & 1 & 1 & 1 & 0 & 0 & 1 & 0 \\
Rhamnocercus rhamnocercus & 0 & 1 & 1 & 0 & 0 & 1 & 1 & 1 & 0 & 0 & 1 & 1 \\
Rhamnocercus bairdiella & 0 & 1 & 1 & 0 & 0 & 1 & 1 & 1 & 0 & 1 & 1 & 1 \\
Rhamnocercus margaritae & 0 & 1 & 1 & 0 & 0 & 1 & 1 & 1 & 0 & 1 & 1 & 1 \\
Rhamnocercus stelliferi & 0 & 1 & 1 & 0 & 0 & 1 & 1 & 1 & 0 & 1 & 1 & 1 \\
\hline
\end{tabular}

* For definition of characters see Table 1

State of Rio de Janeiro, Brazil (CHIOC); Coleção Helmintológica do Museu de Zoologia da Universidade de São Paulo, São Paulo, State of São Paulo, Brazil (CHMZUSP); and Institute of Parasitology, Academy of Sciences of the Czech Republic, České Budějovice, Czech Republic (IPCR).

Twelve characters (Table 1), representing 24 character states, were used in the reconstruction of the phylogenetic relationships of species of Rhamnocercinae. The characters were obtained from the literature or through the study of type specimens and vouchers. Lepidotrema therapon Johnston et Tiegs, 1922 was used as outgroup, based on the phylogenetic relationships of the genera of Diplectanidae (Domingues 2004). The matrix (Table 2) was constructed using the program Nexus Data Editor 0.5.0 (Page 2001). The phylogenetic hypothesis was constructed with the program PAUP $4.0 \mathrm{~b} 10$ (Swofford 2001), using exhaustive search (BandB and addseq = furthest). Bremer support for the respective nodes was determined using the program TreeRot (Sorenson 1999). All characters are considered unordered and with equal weight. Rooting was accomplished a posteriori as proposed by Nixon and Carpenter (1993).
Specimens studied. Rhamnocercoides menticirrhi, Museo de Historia Natural - Universidad National Mayor de San Marcos (MHN-UNMSM), Peru, MHN-UNMSM 1729 (1 voucher); Rhamnocercus bairdiella, United States National Parasites Collection (USNPC), USA, USNPC 49346 (5 paratypes); Rhamnocercus margaritae, Museo Oceanológico Benign Hermano Roman, Estación de Investigaciones Marinas de Margarita (MOBR-EDIMAR), Venezuela, MOBREDIMAR I-617 (1 paratype); Rhamnocercus oliveri, MHNUNMSM 1727 (1 voucher); Rhamnocercus rhamnocercus USNPC 49426 (1 paratype); Rhamnocercus stelliferi, MHNUNMSM 1729 (1 voucher); Rhamnocercus sp., Coleção Helmintológica do Instituto Oswaldo Cruz (CHIOC), Brazil, CHIOC 32590 a-c; Rhamnocercus stichospinus, CHIOC 33959 a-f, CHMZUSP 6138 a-k, and IPCR M-419 (vouchers). 


\section{RESULTS}

\section{Taxonomic revision}

POLYONCHOINEA Bychowsky, 1937

DACTYLOGYRIDEA Bychowsky, 1937

D i p l e c t a n id a e Monticelli, 1903

\section{Rhamnocercinae Monaco, Wood et Mizelle, 1954}

Emended diagnosis. Body fusiform, comprising cephalic region, trunk, peduncle, haptor. Tegument smooth or scaled. Cephalic glands unicellular, lateral or posterolateral to pharynx. Eyes 2 or 4 . Mouth subterminal, midventral. Pharynx muscular, glandular. Intestinal caeca 2, non-confluent posteriorly, lacking diverticula. Peduncular spines with anterior and posterior roots. Haptor laterally expanded, armed with spines; three transverse bars, one midventral, two laterodorsal; two pairs of anchors: ventral and dorsal. Ventral and dorsal anchors with poorly developed superficial root. Squamodiscs present or absent. Male copulatory organ (MCO) tubular, comprising 2 nested tubes (tube within a tube); MCO directed posteriorly; accessory piece absent. Vas deferens apparently looping left intestinal cecum. Germarium looping right caecum. Vagina sinistral, ventral; sclerotized or muscular. Parasites of marine and freshwater Sciaenidae.

Included genera. Rhamnocercus Monaco, Wood et Mizelle, 1954; Rhamnocercoides Luque et Iannacone, 1991; Spinomatrix Boeger, Fehlauer et Marques, 2006.

Remarks. Most species of Rhamnocercinae are described as having posteriorly confluent intestinal caeca (Hargis 1955, Luque and Iannacone 1991, Zambrano 1997, Chaves et al. 1999). Based on this character, Oliver (1987) removed Rhamnocercinae from Diplectanidae and elevated it to the family category within Heterotesioidea Euzet et Dossou, 1979. However, vouchers of Rhamnocercoides stichospinus and Spinomatrix penteormos clearly present non-confluent intestinal caeca. This characteristic is apparently symplesiomorphic for Diplectanidae (see Kritsky and Boeger 1989) and, consequently to the rhamnocercines and, thus, does not support the taxonomic change of Oliver (1987).

Several authors have discussed the homology of the peduncular spines (= echinodisc), observed in Rhamnocercinae with the accessory adhesive organs (squamodiscs, lamellodiscs) reported from other diplectanids. Hargis (1955) and Seamster and Monaco (1956) discussed the validity of Rhamnocercinae based on the origin of the echinodiscs and squamodiscs (see comment above). Bychowsky (1957) suggested that Rhamnocercinae and species of Lepidotrema are closely related due to the presence of spines in the peduncle and haptor, and considered squamodiscs to be homologous with these spines. Oliver (1993) considered that the relatively similar morphology between echinodiscs and lamellodiscs results from a common origin. However, the peduncular spines differ in morphology and position from squamodiscs/lamellodiscs, suggesting that they are not homologous, and that these spines probably represent a unique characteristic shared by species of Rhamnocercinae. The hypothesis of non-homology of these structures is corroborated by the simultaneous presence of squamodiscs and peduncular spines in Spinomatrix penteormos as already suggested by Boeger et al. (2006).

We propose that the term "echinodisc" (Oliver 1987, Luque and Iannacone 1991, Oliver 1993, Zambrano 1997, Desdevises et al. 2001) must be abandoned because it has been historically associated with the homology between the spines and squamodiscs. Alternatively, the term "peduncular spines" is suggested here for these structures.

\section{Rhamnocercoides Luque et Iannacone, 1991}

Emended diagnosis. Tegument smooth or scaled. Cephalic lobes moderately developed; three to four pairs of bilateral head organs. Eyes 4; eye granules small, ovate. Peduncular spines ventral and dorsal, with anterior root several times smaller than posterior root. Ventral bar with anteromedial constriction; posteromedial projection present. Ventral and dorsal haptoral accessory spines at level of ventral bar and lateral lobes of haptor; spines directed anteriorly; more than 6 spines at level of ventral bar; distal portion of each medial spine fan-like. Distal portion of external tube of male copulatory organ (MCO) twisted. Vagina sinistral, sclerotized or not. Vitellaria follicular, restricted to trunk. Type species: Rhamnocercoides menticirrhi Luque et Iannacone, 1991 from Menticirrhus ophicephalus (Jenyns, 1840) [type host].

Included species. Rhamnocercoides stichospinus (Seamster et Monaco, 1956) comb. n. from the gills of Micropogonias undulatus (Linnaeus, 1766) [type host], Menticirrhus americanus (Linnaeus, 1758) and Menticirrhus littoralis (Holbrook, 1855).

Remarks. Rhamnocercoides was proposed by Luque and Iannacone (1991) to include species having (1) peduncular spines (= echinodisc) organized in concentric rows, (2) absence of dorsal echinodisc, and (3) MCO with an accessory piece (copulatory complex). The arrangement of the spines could not be confirmed from the study of available specimens (see comments of the type species below). Luque and Iannacone (1991) confused the distal portion of the external tube of $\mathrm{MCO}$ with an accessory piece. As in the other species of Rhamnocercinae, the MCO of $R$. menticirrhi is composed of two nested tubes and lacks an accessory piece.

Species of Rhamnocercoides resemble those of Rhamnocercus by having peduncular spines with the anterior root shorter than the posterior root. However, species of Rhamnocercoides may be differentiated from Rhamnocercus spp. by having (1) medial constriction in the ventral bar and (2) more than six haptoral accessory spines at the level of the ventral bar. 
Rhamnocercoides menticirrhi Luque et Iannacone, 1991

Figs. 1-5

Type host and locality: Menticirrhus ophicephalus, Chorillos, Peru.

$\mathrm{S}$ p e c i m e n s t u d i e d : 1 voucher (MHN-UNMSM 1729) from Menticirrhus ophicephalus (Jenyns, 1840) (Sciaenidae) from Chorillos, Peru (erroneously labeled as Rhamnocercus menticirrhi).

Remarks. This species requires redescription. The only voucher available from the collection of the Museo de Historia Natural, Universidad National Mayor de San Marcos, stained with Semichon's acetocarmine, is strongly overstained and flattened and, thus, unsuitable for determination of internal features. Luque and Iannacone (1991) stated that $R$. menticirrhi has two rows of concentric hook-like spines. However, the available voucher specimens presented only a few spines, randomly distributed in the haptor; these spines are probably part of the sclerotized complex described by these authors. The comparison of these structures with the peduncular spines of other rhamnocercines suggests that they are not homologous. Scars on the peduncle in the studied specimen suggest that the peduncular spines might have been lost. The observed spines likely represent an autapomorphy for $R$. menticirrhi. The presence of a sclerotized vagina, reported by Luque and Iannacone (1991), could not be confirmed due to the poor condition of the available specimen.

\section{Rhamnocercoides stichospinus (Seamster et}

Monaco, 1956) comb. $\mathrm{n}$.

Figs. 6-15

Synonymy: Rhamnocercus stichospinus Seamster et Monaco, 1956

Redescription. Based on voucher specimens from CHMZUSP and IPCR. Body $590(420-700 ; \mathrm{n}=7)$ long, fusiform; greatest width $83(60-100 ; n=8)$ usually at level of germarium. Tegument scaled in posterior area of body, easily lost in preserved specimens. Cephalic area with poorly developed terminal lobes; three pairs of conspicuous head organs. Eyes 4, equidistant; granules ovate, elongate. Pharynx $31(29-33 ; \mathrm{n}=6)$ in diameter. Posterior peduncular spines larger than anterior spines; two longitudinal rows of acicular spines associated with peduncular spines. Haptoral accessory spines at level of ventral bar forming a divergent row ("V" shape) with posterior spines smaller than anterior spines. Haptor 100 $(80-120 ; n=4)$ long; $148(120-180 ; n=5)$ wide. Ventral anchor $55(47-68 ; n=8)$ long, with elongate deep root, short depressed superficial root, straight shaft and recurved point; point reaching level of tip of superficial root; superficial root $4(4-5 ; \mathrm{n}=4)$ long; deep root 20 $(17-24 ; \mathrm{n}=6)$ long. Dorsal anchor $57(46-72 ; \mathrm{n}=5)$ long, with elongate deep root, inconspicuous superficial root, straight shaft and recurved short point; deep root $23(19-30 ; n=5)$ long. Ventral bar $130(95-160 ; n=7)$
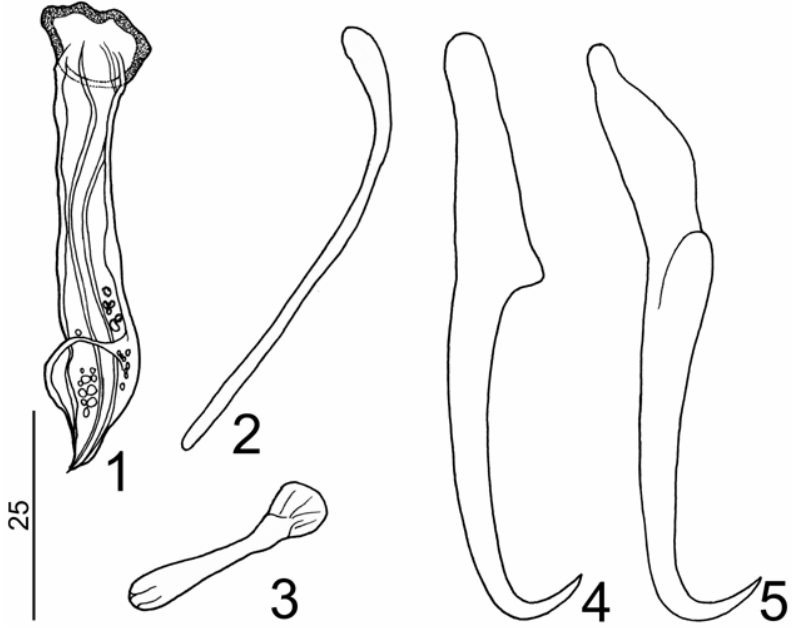

Figs. 1-5. Sclerotized structures of Rhamnocercoides menticirrhi. Fig. 1. Male copulatory organ. Fig. 2. Haptoral accessory sclerite. Fig. 3. Haptoral accessory spines at the level of the ventral bar. Fig. 4. Dorsal anchor. Fig. 5. Ventral anchor. Scale bar for Figs. $1-5$ in $\mu \mathrm{m}$.

long, elongate, with delicate tapered ends; posteromedial projection and anteromedial constriction of ventral bar present. Dorsal bars each $78(60-96 ; n=6)$ long, medial end round. Hooks similar; each 10-11 ( $\mathrm{n}=$ 9) long, with protruding thumb with slightly depressed tip, delicate point and slender shank; hook pair 1 at level of ventral bar; hook pair 5 at level of distal ventral anchor shaft, others submarginal in lateral haptoral lobes; filamentous hook loop (FH loop) shank length. MCO straight, $71(65-85 n=12)$ long; internal tube well separated from external tube (not collapsed); distal portion of the external tube expanded and twisted. Testis 49 (n $=1)$ long, $36(\mathrm{n}=1)$ wide; 2 prostatic reservoirs, bilateral to MCO. Germarium $55(\mathrm{n}=2)$ long, $24(22-25 ; \mathrm{n}$ $=2$ ) wide; ootype not observed; vaginal aperture sinistral; vagina saccate with heavily sclerotized proximal portion, frequently containing apparent spermatophore. Vitellaria extending throughout trunk, absent in regions of major reproductive organs. Semicircular muscular ring posterior to the testis, dorsal. Egg spherical, 61 $(56-65 ; \mathrm{n}=2)$ long, $48(45-50 ; \mathrm{n}=2)$ wide.

Ty pe host and loc a 1 it y: Micropogonias undulatus (Linnaeus, 1766) (Sciaenidae), South Jetty, Port Arkansas, Texas, USA.

O the r h o s t s: Menticirrhus americanus (Linnaeus, 1758) from Rio de Janeiro, Brazil and from Paraná, Brazil (see Chaves et al. 1999); Menticirrhus littoralis (Holbrook, 1855) from South Jetty, Port Arkansas, Texas, USA (see Zwerner and Lawler 1972).

$\mathrm{S}$ p e c i m e n s s t u d i d : 23 vouchers from Menticirrhus americanus (CHIOC 33959 a-f; CHMZUSP 6138 a-k, IPCR M-419). 

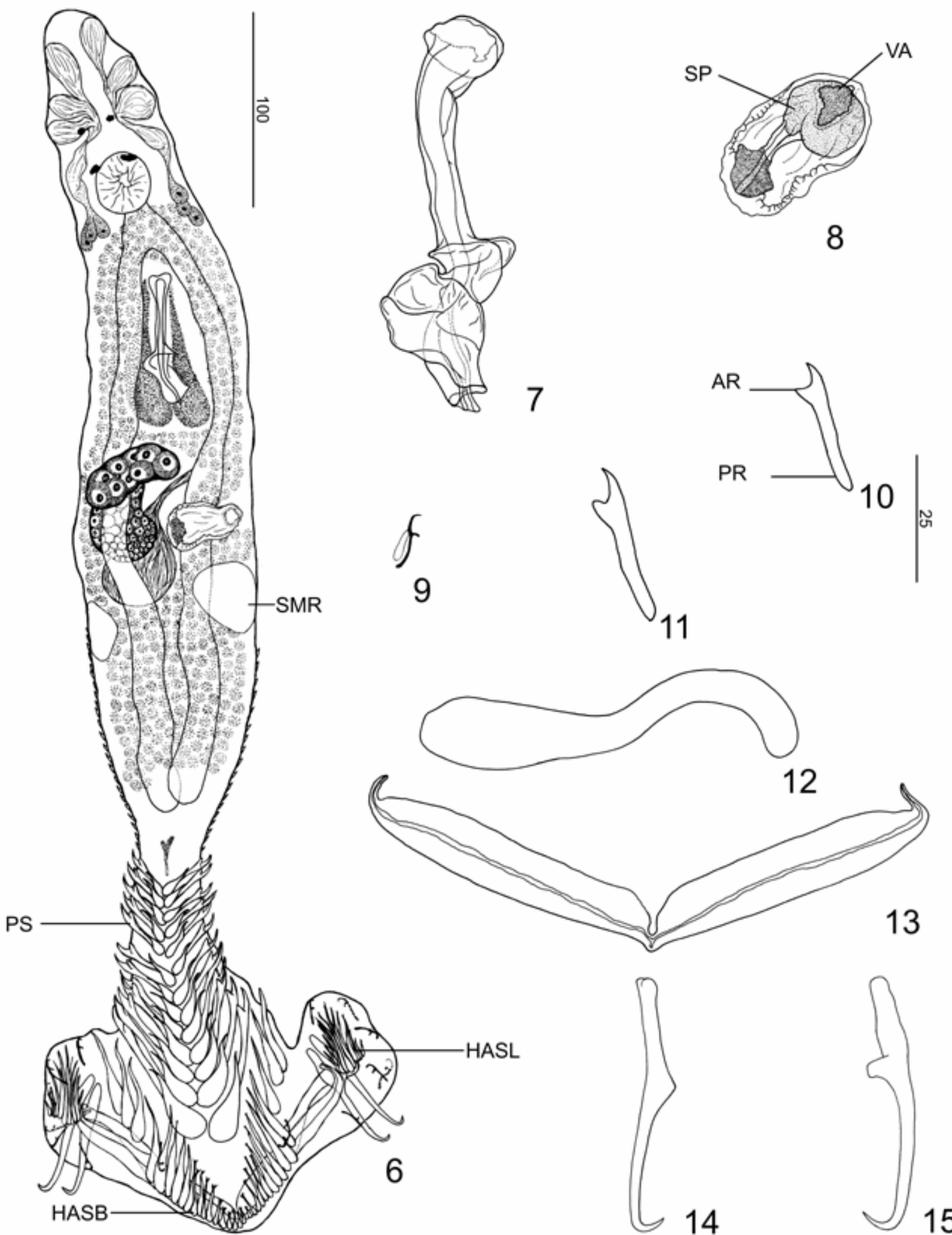

Figs. 6-15. Rhamnocercoides stichospinus comb. n. Fig. 6. Voucher (composite, ventral view). Fig. 7. Male copulatory organ. Fig. 8. Vagina. Fig. 9. Hook. Figs. 10, 11. Peduncular spines. Fig. 12. Sinistral dorsal bar. Fig. 13. Ventral bar. Fig. 14. Dorsal anchor. Fig. 15. Ventral anchor. AR - anterior root; HASB - haptoral accessory spines at the level of the ventral bar; HASL haptoral accessory spines associated with haptoral lobes; PR - posterior root; PS - peduncular spines; SMR - semicircular muscular ring; SP - spermatophore; VA - vaginal aperture. Scale bars: Fig. 6 - $100 \mu \mathrm{m}$; Figs. $7-15-25 \mu \mathrm{m}$. 
Remarks. The original description of Rhamnocercus stichospinus (see Seamster and Monaco 1956) is accurate but there are no illustrations of the internal morphology. A whole-mount illustration was presented for the first time by Chaves et al. (1999) in the redescription based on specimens from Menticirrhus americanus of the Brazilian coast. These authors characterized this species as having posteriorly confluent intestinal caeca and extended this diagnostic character to all known species of Rhamnocercus. The specimens deposited by Chaves et al. (1999) in CHIOC (33959 a-f) are flattened and cleared, and, thus, the distal portions of the caeca could not be observed. However, study of specimens collected from the coast of Paraná State, Brazil, allowed confirmation that the intestinal caeca are not confluent, but partially overlapping (Fig. 6).

This species, originally described in Rhamnocercus, is transferred to Rhamnocercoides as Rhamnocercoides stichospinus comb. $\mathrm{n}$. based on the following synapomorphies: (1) median constriction in the ventral bar and (2) distal portion of each medial haptoral accessory spine fan-like. Rhamnocercoides stichospinus differs from $R$. menticirrhi by (1) absence of two concentric rows of haptoral accessory spines and (2) size and ornamentation of MCO.

\section{Rhamnocercus Monaco, Wood et Mizelle, 1954}

Emended diagnosis. Tegument smooth or scaled. Cephalic lobes poorly developed; three or four pairs of bilateral head organs. Eyes 4; granules small, ovate. Peduncular spines ventral and dorsal, with anterior root several times smaller than posterior root. Ventral bar with posteromedial projection. Ventral and dorsal haptoral accessory spines directed anteriorly, at level of ventral bar and lateral lobes of haptor; 3 or 6 spines at level of ventral bar; distal portion of each spine acicular. MCO tubular, straight or sinuous, with internal tube collapsed against the external tube. Vagina sinistral, sclerotized or not. Vitellaria follicular, restricted to trunk. Type species: Rhamnocercus rhamnocercus Monaco, Wood et Mizelle, 1954 from Umbrina roncador Jordan et Gilbert, 1882 (Sciaenidae) [type host].

Included species. Rhamnocercus bairdiella Hargis, 1955, from the gills of Bairdiella chrysoura (Lacépède, 1802); Rhamnocercus margaritae Zambrano, 1997, from the gills of Bairdiella ronchus (Cuvier, 1830); Rhamnocercus oliveri Luque et Iannacone, 1991, from the gills of Stellifer minor (Tschudi, 1846); Rhamnocercus stelliferi Luque et Iannacone, 1991 from the gills of Stellifer minor (Tschudi, 1846); Rhamnocercus sp. from the gills of Micropogonias furnieri (Desmarest, 1823).

Remarks. Features that distinguish species of Rhamnocercus from species of other genera of Rhamnocercinae include the combined presence of (1) peduncular spines ventral and dorsal, with anterior root several times shorter than posterior root; (2) ventral bar with posteromedial projection; (3) ventral and dorsal haptoral accessory spines directed anteriorly, at the level of the ventral bar and lateral lobes of the haptor; (4) 3 or 6 haptoral accessory spines at the level of the ventral bar; (5) distal portion of each spine acicular; and (6) MCO with internal tube collapsed against the external tube.

Rhamnocercus rhamnocercus Monaco, Wood et Mizelle, 1954 Figs. 16-24

Type host and locality: Umbrina roncador Gilbert et Jordan, 1882 (Sciaenidae), Florida, USA.

$\mathrm{S} \mathrm{p}$ e c i m e $\mathrm{n}$ s t u d i e d : 1 paratype from Umbrina roncador from Florida, USA (USNPC 49426).

Remarks. The original description of $R$. rhamnocercus presented by Monaco et al. (1954) contains limited information on internal morphology. The paratype (USNPC 49426) is overly flattened and cleared and is, thus, insufficient for determination of features of internal morphology and redescription.

Rhamnocercus rhamnocercus is characterized by presenting (1) long and straight MCO (Fig. 16) and (2) three haptoral accessory spines at the level of the ventral bar. The middle spine (indicated as 2 in Fig. 20) is smaller than the bilateral spines (indicated as 1 and 3 in Fig. 20).

Kohn et al. (1989) reported $R$. rhamnocercus from Micropogonias furnieri from the Brazilian southeast. However, analysis of the deposited specimens (CHIOC $32590 \mathrm{a}-\mathrm{c}$ ) demonstrated that they most likely represent an undescribed species of Rhamnocercus. It differs from all other species of Rhamnocercus by having the MCO with the internal tube well separated from external tube, subterminal opening and the distal tip of external tube with tooth-like projections. Unfortunately the specimens are not in good condition, limiting their use for a formal description and inclusion in the phylogenetic analysis.

\section{Rhamnocercus bairdiella Hargis, 1955 Figs. 25-30}

$\mathrm{T}$ y p e hos t and 1 o c a 1 i t y : Bairdiella chrysoura (Lacépède, 1802) (Sciaenidae), Florida, USA.

$\mathrm{S}$ p e c i m e n s t u d i e d : 5 paratypes from Bairdiella chrysoura (Lacépède, 1802) (Sciaenidae) from California, USA (USNPC 49346).

Remarks. Hargis (1955) described the copulatory complex of $R$. bairdiella as composed of an MCO and an accessory piece, and referred to confluent intestinal caeca. However, analysis of the paratypes (USNPC 49346) indicated that the structure referred to by Hargis (1955) as an accessory piece represents an expansion of the distal portion of the MCO. The confluence of the intestinal caeca could not be verified in these specimens.

Rhamnocercus bairdiella resembles $R$. margaritae Zambrano, 1997 based on the morphology of MCO (long and sinuous) (Figs. 25, 31) and on the presence of three haptoral accessory spines at the level of the ventral bar (middle spine smaller than others) (Figs. 30, 35). 

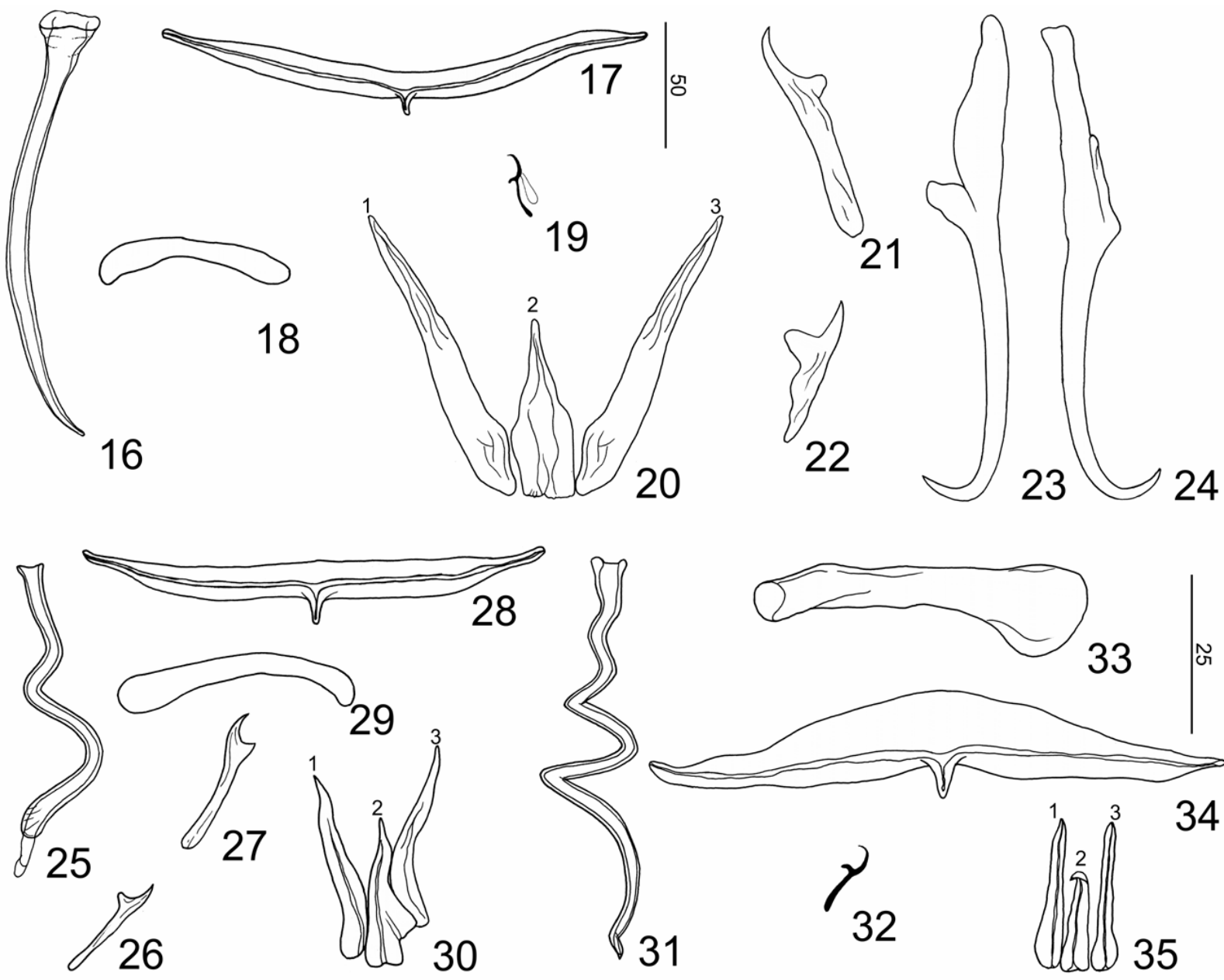

Figs. 16-35. Sclerotized structures of species of Rhamnocercus. Figs. 16-24. R. rhamnocercus. Fig. 16. Male copulatory organ. Fig. 17. Ventral bar. Fig. 18. Dextral dorsal bar. Fig. 19. Hook. Fig. 20. Haptoral accessory spines at the level of the ventral bar. Figs. 21, 22. Peduncular spines. Fig. 23. Ventral anchor. Fig. 24. Dorsal anchor. Figs. 25-30. R. bairdiella. Fig. 25. Male copulatory organ. Figs. 26, 27. Peduncular spines. Fig. 28. Ventral bar. Fig. 29. Sinistral dorsal bar. Fig. 30. Haptoral accessory spines at the level of the ventral bar. Figs. 31-35. R. margaritae. Fig. 31. Male copulatory organ. Fig. 32. Hook. Fig. 33. Dextral dorsal bar. Fig. 34. Ventral bar. Fig. 35. Haptoral accessory spines at the level of the ventral bar. Figs. 20, 30, 35: numbers 1-3 indicate the sequence described in the text. Scale bars: Figs. 16, 19-35-25 $\mu \mathrm{m}$; Figs. 17, $18-50 \mu \mathrm{m}$.

\section{Rhamnocercus margaritae Zambrano, 1997}

Figs. 31-35

Ty pe host and 1 o c a lity: Bairdiella ronchus $(\mathrm{Cu}-$ vier, 1830) (Sciaenidae), Giela y Isleta, Lagoon of La Restinga, Venezuela.

$\mathrm{S} \mathrm{p} \mathrm{e} \mathrm{c} \mathrm{i} \mathrm{m} \mathrm{e} \mathrm{n} \mathrm{s} \mathrm{t} \mathrm{u} \mathrm{d} \mathrm{i} \mathrm{e} \mathrm{d} \mathrm{:} \mathrm{1} \mathrm{paratype} \mathrm{of} \mathrm{Bairdiella} \mathrm{ronchus}$ (Cuvier, 1830) (Sciaenidae) from Venezuela (MOBREDIMAR I-617).

Remarks. Zambrano (1997) described R. margaritae from the gills of Bairdiella ronchus from Venezuela. Although the author reported the presence of one dorsal bar, two ventral bars, and 12 haptoral hooks, the paratype specimen studied has two dorsal bars, a ventral bar and 14 haptoral hooks (as do other species of diplectanids). This author also did not describe the posteromedial projection of the ventral bar, a structure clearly observable in the paratype. Finally, the legends for the figures of $R$. margaritae in Zambrano's description are switched with the legends of the figures of $\mathrm{Di}$ plectanum magnodiscatum, described in the same publication.

Rhamnocercus margaritae most closely resembles $R$. bairdiella, based on the morphology of the MCO. Zambrano (1997) differentiates $R$. margaritae from $R$. bairdiella by the presence of four pairs of head organs (three pairs in R. bairdiella) and the presence of "bifid spines in the equinodisc" (= roots of the peduncular spines) (absent in $R$. bairdiella). It was not possible to confirm the number of head organs of the paratype specimen of $R$. margaritae (MOBR-EDIMAR I-617) and $R$. bairdiella (USNPC 49346). However, the analysis of specimens of Rhamnocercus bairdiella confirmed the presence of anterior and posterior roots in the peduncular spines (Figs. 26, 27). Further, R. margaritae can be differentiated from $R$. bairdiella by the morphol- 
ogy of the ventral bar (more robust in the anteromedial portion) (Fig. 34) and the size of the MCO (longer than the MCO of R. bairdiella) (Fig. 31).

\section{Rhamnocercus oliveri Luque et Iannacone, 1991}

Figs. 36-40

Type host and 1 o c a lity: Stellifer minor (Tschudi, 1846) (Sciaenidae), Chorillos, Peru.

$\mathrm{S} p$ e c i m e n s t u d i e d : 1 voucher from Stellifer minor (Tschudi, 1846) (Sciaenidae) from Chorillos, Peru (MHNUNMSM 1727) (labeled erroneously as Rhamnocercus stelliferi).

Remarks. The specimen studied (MHN-UNMSM 1727), stained with Semichon's acetocarmine, is overstained and flattened, and it unsuitable for determination of internal features and the MCO. The original description of this species, presented by Luque and Iannacone (1991), indicated that the haptor is armed with 6 haptoral accessory spines at the level of the ventral bar. However, the type specimen has only three spines in the haptor, as described for $R$. rhamnocercus, $R$. bairdiella and $R$. margaritae.

Rhamnocercus oliveri can be differentiated from all other congeneric species by the morphology of the MCO (straight and short) and presence of a sclerotized vagina.

Rhamnocercus stelliferi Luque et Iannacone, 1991

Figs. 41-46

T y p e ho s t: Stellifer minor (Tschudi, 1846) (Sciaenidae), Chorillos, Peru.

$\mathrm{S} p$ e c i m e n s t u d i e d : 1 voucher from Stellifer minor (Tschudi, 1846) (Sciaenidae) from Chorillos, Peru (MHNUNMSM 1846) (erroneously labeled Rhamnocercus oliveri).

Remarks. The available specimen does not allow confirmation of the internal morphology and of the hap- toral armament (peduncular spines and haptoral accessory spines at the level of the ventral bar). This species resembles $R$. margaritae and $R$. bairdiella based on the morphology of the MCO. Rhamnocercus stelliferi differs from these two species by the comparative morphology of the haptoral accessory spines at the level of the ventral bar (spines of same size in $R$. stelliferi in contrast with a smaller middle spine in $R$. margaritae and $R$. bairdiella).

Spinomatrix Boeger, Fehlauer et Marques, 2006

Diagnosis. Tegument thin, smooth. Cephalic lobes poor developed; three pairs of bilateral head organs. Eyes 4. Peduncular spines ventral and dorsal; with anterior root twice bigger than posterior root. Ventral bar with antero-medium constriction, two short submedian, posterior projections for articulation of dorsal bar. Ventral sub-globose, muscular structure bearing spines disposed in rosette. Male copulatory organ straight, formed by two nested tubes; external tube twisted. Vagina sinistral, muscular. Vitellaria dense, co-extensive with intestinal caeca. Type species: Spinomatrix penteormos Boeger, Fehlauer et Marques, 2006 from Pachyurus adspersus Steindachner, 1869 (Sciaenidae) [type host].

$\mathrm{S}$ p e c i m e n s s t u d i e d : Holotype (CHMZUSP 5947a) and 6 paratypes (CHIOC 36502a-f) of $S$. penteormos from Pachyurus adspersus Steindachner, 1869 (Sciaenidae) from Jusante Cachoeirinha da Brecha, Rio Piranga, municipality of Vau-Açu, State of Minas Gerais, Brazil.

Remarks. This genus is monotypic. Spinomatrix penteormos is the only member among Rhamnocercinae that occurs in a freshwater sciaenid, Pachyurus adspersus (Pachyurinae) from Rio Piranga, Basin of Rio Doce, Brazil. Spinomatrix penteormos is included in Rhamnocercinae based on the presence of peduncular spines. Spinomatrix penteormos resembles species of Rhamnocercoides in the morphology of the $\mathrm{MCO}$ and the

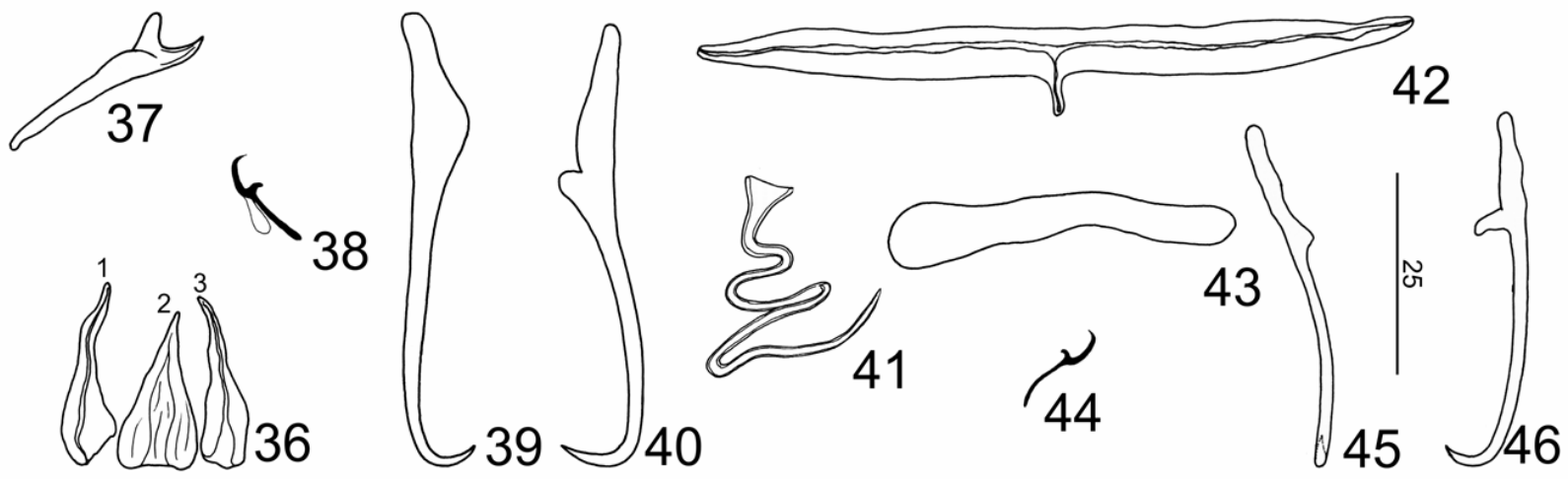

Figs. 36-46. Sclerotized structures of species of Rhamnocercus. Figs. 36-40. R. oliveri. Fig. 36. Haptoral accessory spines at the level of the ventral bar. Fig. 37. Peduncular spines. Fig. 38. Hook. Fig. 39. Dorsal anchor. Fig. 40. Ventral anchor. Figs. 41-46. R. stelliferi. Fig. 41. Male copulatory organ. Fig. 42. Ventral bar. Fig. 43. Sinistral dorsal bar. Fig. 44. Hook. Fig. 45. Dorsal anchor (tip bent). Fig. 46. Ventral anchor. Fig. 36: numbers 1-3 indicate the sequence described in the text. Scale bar for Figs. 36-46 in $\mu \mathrm{m}$. 
presence of multiple haptoral accessory spines at the level of the ventral bar. However, Spinomatrix penteormos can be differentiated from species of Rhamnocercoides and Rhamnocercus by the morphology of the peduncular spines (peduncular spine with anterior root longer than posterior root) and the presence of squamodiscs (absent in all the other species of the subfamily).

\section{Phylogeny}

The phylogenetic hypothesis presented in Fig. 47 represents the single most parsimonious tree produced through the program PAUP 4.0b10 using 12 characters (length $=13$; C.I. index $=92 \%$; R.I. $=94 \%$ ). The species of Rhamnocercinae share a single synapomorphy, the presence of peduncular spines with roots. According to the hypothesis, Spinomatrix penteormos, the only freshwater representative of Rhamnocercinae, is sister taxon to the clade that includes all other species. Rhamnocercoides menticirrhi and $R$. stichospinus are sister species based on two synapomorphies, both with consistency index of 100\%: (1) haptoral accessory spines at the level of the ventral bar with fan-like distal extremity and (2) anteromedial constriction in the ventral bar. This result supports the transfer of Rhamnocercus stichospinus to Rhamnocercoides.

The remaining five species, all members of Rhamnocercus ( $R$. oliveri, $R$. rhamnocercus, $R$. stelliferi, $R$. bairdiella, and $R$. margaritae) form a clade, supported by the sharing of (1) 3 or 6 haptoral accessory spines at the level of the ventral bar, and (2) a uniform distal portion of the external tube of the MCO. Although R. stelliferi, $R$. bairdiella and $R$. margaritae are putative sister species, their phylogenetic relationship could not be resolved.

\section{DISCUSSION}

Questions on the "status" of Rhamnocercinae within Diplectanidae started with the description of Rhamnocercus bairdiella by Hargis (1955). This author described the intestinal caeca as "apparently confluent". Kritsky et al. (2000) indicated that this interpretation of the intestinal morphology of some species of Rhamnocercinae might have been incorrect, thereby limiting the value of this feature as justification for the elevation of this subfamily to the family level, as proposed by Oliver (1987). Confluent intestinal caeca were not observed in the present study of available specimens of Rhamnocercus bairdiella, $R$. rhamnocercus, Rhamnocercoides menticirrhi, $R$. oliveri and $R$. stelliferi. However, the analysis of specimens of Rhamnocercoides stichospinus and of Spinomatrix penteormos confirms that the intestinal caeca in these species are indeed blind, as foreseen by Kritsky et al. (2000), and not confluent, as presumed by Hargis (1955), Oliver (1987), Luque and Iannacone (1991) and Chaves et al. (1999).

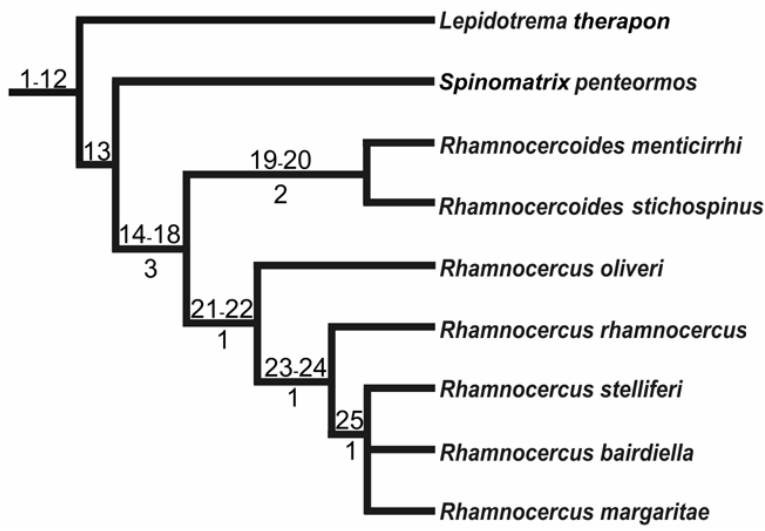

Fig. 47. Hypothesis for the phylogenetic relationships for Rhamnocercinae based on 12 morphologic characters. Lepidotrema therapon is presented as outgroup. Numbers above the branches refer to postulated evolutionary changes. Numbers below branches indicate respective Bremer support.

The analysis of type and voucher specimens of Rhamnocercus stichospinus and the phylogenetic analysis confirm that this species shares many features with Rhamnocercoides menticirrhi, suggesting that these two species are congeneric. Both species share general morphology, arrangements of the haptoral structures, and morphology of the male copulatory organ. The sharing of these features supports the transfer of Rhamnocercus stichospinus to Rhamnocercoides.

Recognition of Spinomatrix as sister group of other Rhamnocercinae is supported by the presence of peduncular spines, a character shared with all these species. The combined presence of squamodiscs and peduncular spines in $S$. penteormos indicates that these structures are not homologous, as proposed by Hargis (1955). The absence of squamodiscs is reported for other Diplectanidae (Lobotrema, Murraytrema, Murraytrematoides, Rhamnocercus, Rhamnocercoides) and it is a likely result of secondary losses, as suggested for the first time for Bychowsky and Nagibina (1977) and corroborated by the cladistic analysis proposed by Domingues (2004).

Acknowledgements. The authors thank the following individuals and agencies for supporting this study: Cesar Santos helped during collection and identification of fish hosts. Eric Hoberg and Patricia Pillit, USNPC; Luís C.M. Pereira and Dely Noronha, CHIOC; Juan Carpelo, MOBR-EDIMAR; Irma Franke and Lidia Sánchez, MHN-UNMSM, allowed access to specimens under their care; Karin H. Fehlauer (Universidade de São Paulo) and Florian Reyda (Connecticut University, USA) provided a presubmission review of the manuscript. This study was partially supported by the Conselho Nacional de Desenvolvimento Científico e Tecnológico (CNPq) and Fundação Coordenação de Aperfeiçoamento de Pessoal de Nível Superior (CAPES). 


\section{REFERENCES}

BOEGER W.A., FEHLAUER K.H., MARQUES, E.E. 2006: Neotropical Monogenoidea. 49. Four new species of the Diplectanidae (Dactylogyrinea) from the gills of some pachyurines (Teleostei, Sciaenidae) from the Rio Tocantins and Rio Doce Basins, with the proposal of Anoplectanum n. g. and Spinomatrix n. g. Syst. Parasitol. (In press; published online 13 April 2006)

BYCHOWSKY B.E. 1957: Monogenetic Trematodes. Their Systematics and Phylogeny. The Academy of Sciences of the USSR, Moscow, 509 pp. Translated from Russian by P.C. Oustinoff (W.J. Hargis, Jr. ed.), American Institute of Biological Science, Washington D.C.

BYCHOWSKY B.E., NAGIBINA L.F. 1977: [About the taxonomic position of some representatives of the monopisthocotylean monogeneans from marine fishes.] Parazitol. Sb. 27: 7-17. (In Russian.)

CHAVES N.N., LUQUE J.L., CEZAR A.D. 1999: Redescription of Rhamnocercus stichospinus Seamster and Monaco, 1956 (Monogenea: Diplectanidae), parasitic on Menticirrhus americanus (Osteichthyes: Sciaenidae) from the Coastal Zone of the State of Rio de Janeiro, Brazil. Mem. Inst. Oswaldo Cruz 94: 615-618.

DESDEVISES Y., MORAND S., OLIVER G. 2001: Linking specialization to diversification in the Diplectanidae Bychowsky 1957 (Monogenea, Platyhelminthes). Parasitol. Res. 87: 223-230.

DOMINGUES M.V. 2004: [Phylogeny and Taxonomy of Diplectanidae Monticelli, 1903 (Platyhelminthes, Monogenoidea)]. Doctoral Dissertation, Graduate Program in Zoology, Universidade Federal do Paraná, Curitiba, 199 pp. (In Portuguese.)

HARGIS W.J., Jr. 1955: Monogenetic trematodes of Gulf of México fishes. Part III. The superfamily Gyrodactyloidea (continued). Quart. J. Florida Acad. Sci. 18: 33-47.

HUMASON G.L. 1979: Animal Tissue Techniques. 4th ed. W.H. Freeman and Company, San Francisco, CA, USA, $661 \mathrm{pp}$.

KOHN A., SANTOS C.P., COHEN S.C. 1989: Monogenea parasites of Micropogonias furnieri (Desmarest, 1823) (Pisces, Sciaenidae) from the littoral of Rio de Janeiro State, Brazil. Mem. Inst. Oswaldo Cruz 84: 291-295.

KRITSKY D.C., BOEGER W.A. 1989: The phylogenetic status of Ancyrocephalidae Bychowsky, 1937 (Monogenea: Dactylogyroidea). J. Parasitol. 75: 207-211.

KRITSKY D.C., JIMÉNEZ-RUIZ F.A., SEY O. 2000: Diplectanids (Monogenoidea: Dactylogyridae) from the gills

Received 16 June 2005 of marine fishes of the Persian Gulf of Kuwait. Comp. Parasitol. 67: 145-164.

LUQUE J.L., IANNACONE J. 1991: Rhamnocercidae (Monogenea: Dactylogyroidea) in Sciaenidae fishes from Perú, with description of Rhamnocercoides menticirrhi n. gen., n. sp. and two new species of Rhamnocercus. Rev. Biol. Trop. 39: 193-201.

MIZELLE J.D. 1936: A species of trematodes from the gills of Illinois fishes. Am. Midl. Nat. 17: 785-806.

MIZELLE J.D., KLUCKA A.R. 1953: Studies on monogenetic trematodes. XIV. Dactylogyridae from Wisconsin fishes. Am. Midl. Nat. 49: 720-733.

MONACO H.L., WOOD R.A., MIZELLE J.D. 1954: Studies on monogenetic trematodes. XVI. Rhamnocercinae new subfamily of Dactylogyridae. Am. Midl. Nat. 52: 129132.

NIXON K.C., CARPENTER J.M. 1993: On outgroup. Cladistics 9: 413-426.

OLIVER G. 1987: Les Diplectanidae Bychowsky 1957 (Monogenea, Monopisthocotylea, Dactylogyridea). Systématique, Biologie, Ontogénie, Écologie, Essai de Phylogénèse. Thèse d'état, Université des Sciences et Techniques du Languedoc, $433 \mathrm{pp}$.

OLIVER G. 1993: Les Diplectanidae Bychowsky, 1957 (Monogenea, Monopisthocotylea, Dactylogyridea) marqueurs biologiques, témoins de la biogéographie et de l'évolution de leurs hôtes. Bull. Zool. Soc. Fr. 118: 25-36.

PAGE R. 2001: Nexus Data Editor for Windows 0.5.0. http://taxonomy.zoology.gla.ac.uk/rod/NDE/nde.htm.

SEAMSTER A., MONACO L.H. 1956: The new species of Rhamnocercinae. Am. Midl. Nat. 55: 180-183.

SORENSON M.D. 1999: TreeRot, version 2. Boston University, Boston, MA.

SWOFFORD D.L. 2001: Phylogenetic Analysis Using Parsimony (*and other methods). Version 4. Sinauer Associates, Sunderland, Massachusetts.

ZAMBRANO J.L.F. 1997: Dos especies nuevas de monogéneos (Diplectanidae) parásitos de peces marinos de la Laguna de la Restinga. An. Inst. Biol. Univ. Nac. Autón. Méx., ser. Zool., 68: 225-236.

ZWERNER D., LAWLER A.R. 1972: Some parasites of Chesapeake Bay fauna, In: M.L. Wass (Ed.), A checklist of the biota of Chesapeake Bay. Virginia Institute of Marine Science Report No. 65, Virginia, USA, pp. 78-94.

Accepted 7 February 2006 